\title{
Echocardiographic prediction of outcome after cardiac resynchronization therapy: conventional methods and recent developments
}

\author{
Geert E. Leenders • Maarten J. Cramer • \\ Margot D. Bogaard • Mathias Meine • \\ Pieter A. Doevendans • Bart W. De Boeck
}

Published online: 21 November 2010

(C) The Author(s) 2010. This article is published with open access at Springerlink.com

\begin{abstract}
Echocardiography plays an important role in patient assessment before cardiac resynchronization therapy (CRT) and can monitor many of its mechanical effects in heart failure patients. Encouraged by the highly variable individual response observed in the major CRT trials, echocardiography-based measurements of mechanical dyssynchrony have been extensively investigated with the aim of improving response prediction and CRT delivery. Despite recent setbacks, these techniques have continued to develop in order to overcome some of their initial flaws and limitations. This review discusses the concepts and rationale of the available echocardiographic techniques, highlighting newer quantification methods and discussing some of the unsolved issues that need to be addressed.
\end{abstract}

Keywords Heart failure $\cdot$ Cardiac resynchronization therapy $\cdot$ Echocardiography $\cdot$ Mechanical dyssynchrony

\section{Introduction}

Cardiac resynchronization therapy (CRT) has been developed along with experimental data indicating a direct effect of conduction disturbances on mechanical coordination, with subsequent deleterious effects on cardiac function, efficiency, structure, and regional gene expression [1-5]. In the clinical setting, large prospective multicenter trials

G. E. Leenders $(\varangle) \cdot$ M. J. Cramer · M. D. Bogaard ·

M. Meine - P. A. Doevendans

Department of Cardiology, University Medical Center Utrecht, P.O. Box 855500, 3508 GA Utrecht, The Netherlands

e-mail: g.e.h.leenders@umcutrecht.nl

B. W. De Boeck

University Hospital Basel, Basel, Switzerland have established CRT to induce reverse remodeling and improve exercise capacity, left ventricular (LV) function and survival in patients with advanced (NYHA III-IV), medication resistant heart failure and ventricular conduction disturbances (the vast majority having left bundle branch block [LBBB]) [6-8]. More recently, CRT has also proven its mechanical and clinical effectiveness in earlier disease stages $[9,10]$. Encouraged by the highly variable response in individual patients observed in major trials $[6,10]$, echocardiography-based measurements of dyssynchrony have been extensively investigated with the aim of improving response prediction and CRT delivery [11-16]. After initial results in single center studies were met by enthusiasm, disillusion and criticism followed because in multicenter trials echocardiography hardly improved the prediction of response to CRT [17, 18]. While for many a reason to abandon the idea of echocardiography-guided prediction and application of CRT [19], it has compelled many others to reconsider the physiologic rationale and technical limitations of echocardiographic approaches and improve them accordingly. In this paper, we critically review the available echocardiographic techniques, their rationale, methods of quantification (time intervals, regional delays, and discoordination) and some of the unsolved issues that need to be addressed before echocardiography can be considered as a reliable tool to predict outcome after CRT.

\section{Echo-physiological principles and rationale}

In the normal heart, electrical and mechanical anatomy and function are closely tuned to each other in a way that ensures a carefully sequenced concatenation of mechanical events, eventually leading to an efficient biventricular filling, contraction and pump function. A "classic" 
conduction disturbance with a LBBB-sequence induces an abnormal and delayed right-to-left transseptal activation and pressure gradient ("interventricular dyssynchrony") and provokes an additional delay in the onset of force development in the posterolateral LV wall compared to the relatively early activated septum ("intraventricular dyssynchrony"). The relative delay in overall LV activation may also cause a prolonged left-sided atrioventricular (AV) delay ("atrioventricular dyssynchrony"). As discussed by Prinzen et al. in this issue of the journal [104], the ensuing imbalances in mechanical forces give rise to inefficient back-and-forth mechanical interactions between and within the ventricles, from now on referred to as "discoordination". This discoordination impairs the pressure and stroke work ability of the heart [2] causes or worsens mitral insufficiency [20] delays and prolongs LV isovolumic events [21] and impairs diastolic filling [21] (Fig. 1). In addition, features of mechanical discoordination such as abnormal wall stretch also entail secondary energetic and molecular effects that play a role in the further disease manifestations [105]. Notwithstanding that electrical dyssynchrony may be the initiator of the unfavorable mechanics, the magnitude of such mechanical interaction ultimately depends on more than electrical dyssynchrony alone (e.g. influence of local loading, contractility, etc.). Accordingly, both experimental as well as clinical studies suggest that mechanical rather than electrical dis- and recoordination predict and ensure effective CRT, respectively [11, 22-25]. As illustrated in Fig. 1 and discussed throughout this paper, many of the abovementioned mechanical events and consequences can be evaluated by echocardiography. Being non-invasive and applicable after CRT, echocardiography can also help us to understand the actual mechanism of CRT. The basic rationale for echocardiographic quantification and monitoring of mechanical dyssynchrony remains therefore valid. In fact, by defining echocardiographically determined LV ejection fraction (LVEF) and dimensions as inclusion and outcome criteria in the major CRT trials, echocardiography has always been an essential and inseparable part of adequate selection and monitoring of this therapy.

\section{Left ventricular time intervals and atrioventricular dyssynchrony}

Conventional Doppler-based quantification of the LV preejection period (LVPEP), total isovolumic time, and total

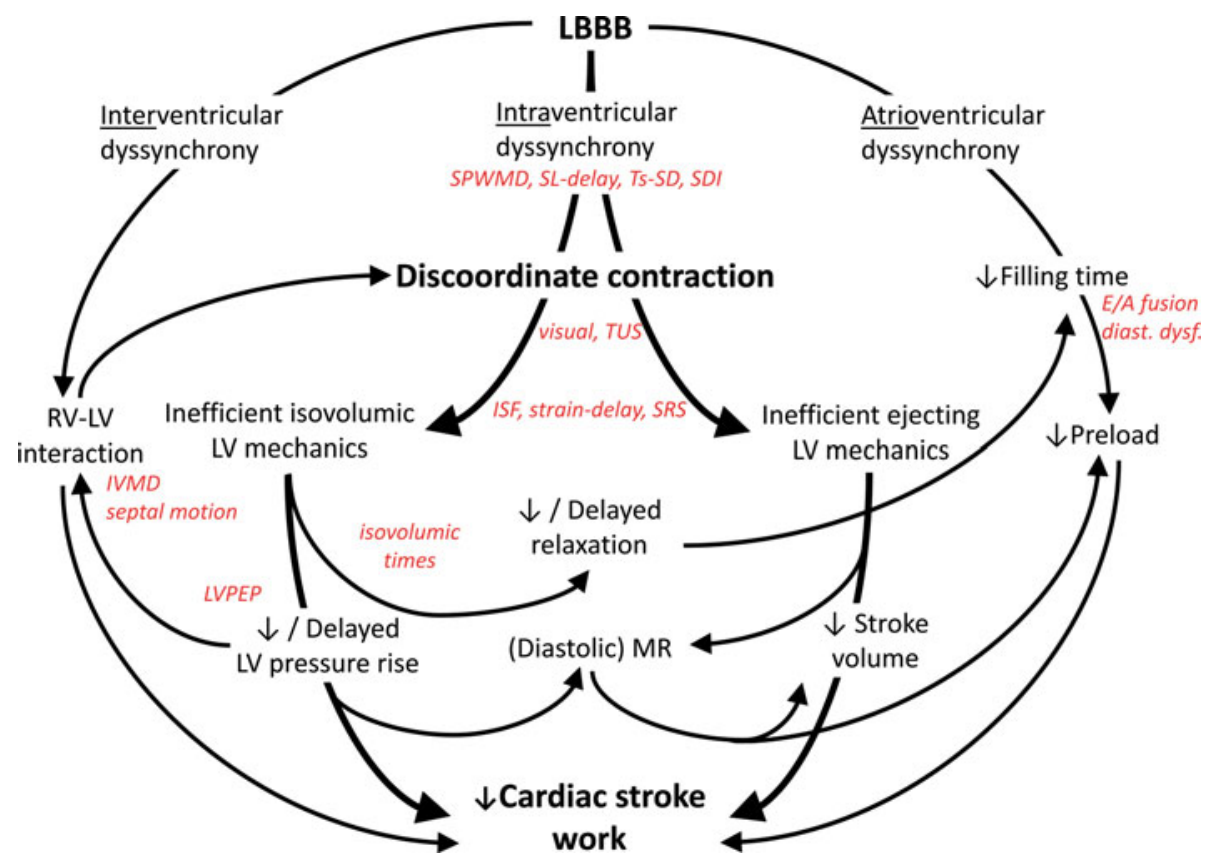

Fig. 1 Mechanical dyssynchrony in left bundle branch block. Schematic representation of the mechanism by which electrical dyssynchrony can cause inefficient (bi-)ventricular filling, contraction, and pump function. Parameters assessable by echocardiography are highlighted in red italics. Of note: intrinsic (local) contractility, elasticity, and loading make that not all delays (=dyssynchrony) necessarily lead to similar mechanical interactions and discoordination. The effects of so-called atrio-, inter- and intraventricular dyssynchrony partially overlap and closely interact, with discoordination induced by intraventricular delays playing a central and determining role at all levels. ISF internal stretch fraction, IVMD interventricular mechanical delay, $L V$ left ventricle, $L V P E P$ left ventricle pre-ejection period, $M R$ mitral regurgitation, $R V$ right ventricle, SDI three-dimensional dyssynchrony index, SL-delay septal-to-lateral delay, $S P W M D$ septal-to-posterior wall motion delay, $S R S$ systolic rebound stretch, $T S-S D$ tissue-Doppler velocity standard deviation, TUS temporal uniformity of strain 
filling time belong to the most straightforward and established techniques to screen for dyssynchrony. As a consequence of intra- (and inter)ventricular discoordination, isovolumic contraction and relaxation are delayed and prolonged at the expense of both ejection and filling [21]. Additionally, the relatively delayed activation and contraction of the LV may induce a functional first degree AVblock and diastolic mitral regurgitation, further aggravating disturbances in LV filling and effective preload (Figs. 1, 2). Inversely, CRT has been shown to immediately optimize preload and filling, to reduce isovolumic periods, and increase stroke volume [8, 26-29]. Besides relating to dyssynchrony at multiple levels, cardiac time intervals are confounded by their sensitivity to altered loading, contractility, and most importantly changes in heart rate. Indexed for RR-interval, filling time and total isovolumic time have been shown to predict response to CRT with roughly the same accuracy as local temporal dyssynchrony measurements, while profiting from an excellent feasibility $(>95 \%)$ and reproducibility (variability $\approx 5 \%$ ) unmatched by any of the latter $[17,28,30]$. Of note, in a typical CRT population, the frequency and relevance of a compromised filling explained by isolated AV dyssynchrony only remains debated. Parsai et al. [31] found compromised filling without evident intraventricular dyssynchrony in $23 \%$ of their population but also found less reverse remodeling in these patients, whereas Lafitte et al. [32] demonstrated compromised filling in about $30 \%$ of their total population. In addition, although routinely performed in the major trials and advised by the American society of echocardiography [33] also the benefits of AV-optimization have not conclusively been shown [34] let alone to be independent of concomitant inter- and intraventricular recoordination as well $[26,35]$.

\section{Interventricular dyssynchrony}

The interventricular mechanical delay (IVMD) estimates the mechanical dyssynchrony between the right ventricle (RV) and the left ventricle (LV). Since right ventricular mechanical events in LBBB occur rather timely, in practice IVMD will to a large extent be driven by the delay in effective LV contraction (e.g. measured by LVPEP), ensuing the right-to-left transseptal pressure gradient in early systole [36, 37]. The former can however also be influenced by circumstances where the associated pressure gradient is modified by significant alterations in right and/ or left ventricular loading [38, 39]. The resulting systolic and diastolic phase differences between RV and LV pressure can be effectively corrected by CRT and are paralleled by acute hemodynamic improvement [37, 38, 40]. The conventional echocardiographic method to quantify IVMD

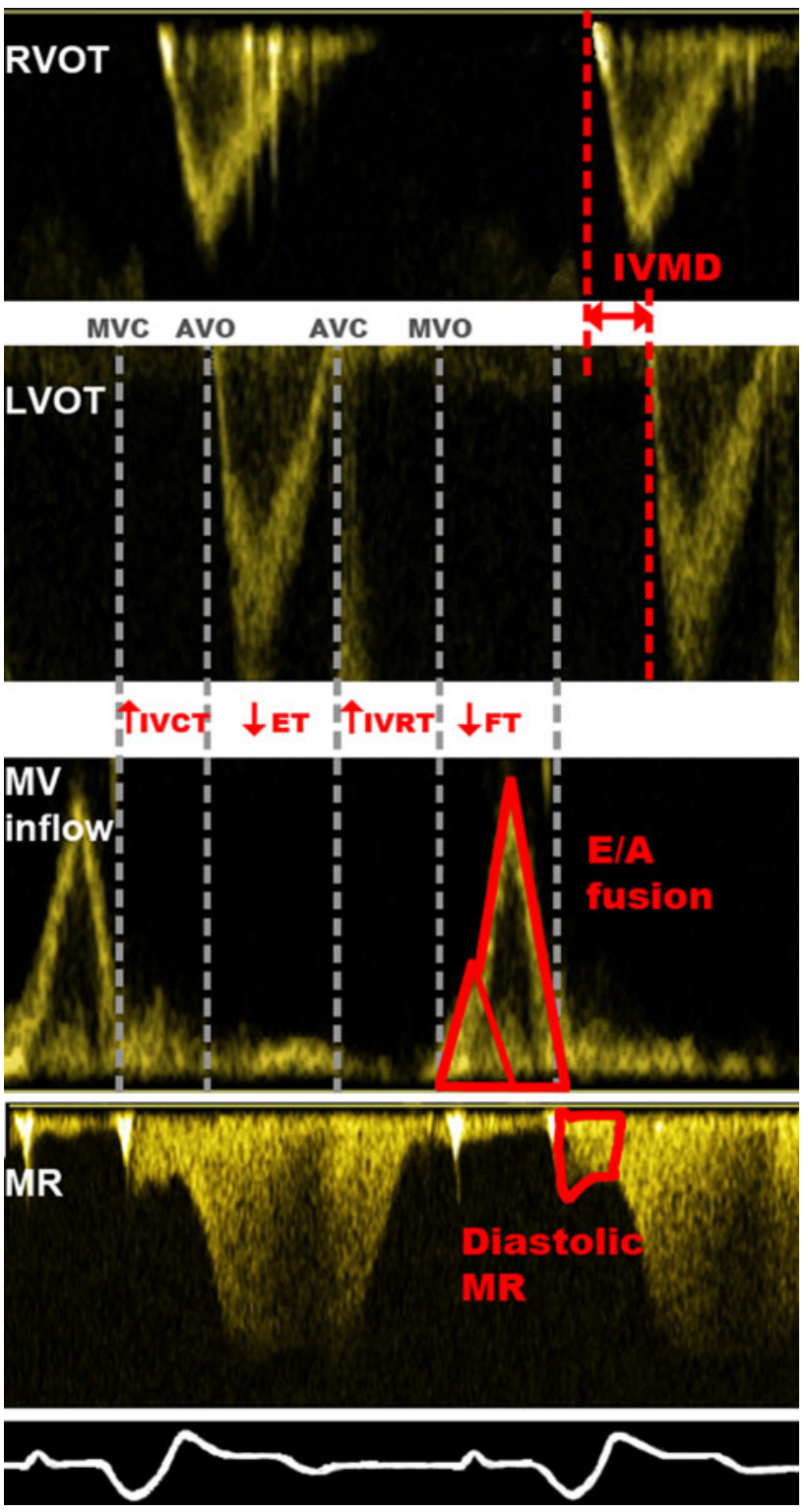

Fig. 2 Global time intervals. The effect of dyssynchrony on global time intervals is illustrated by Doppler registrations over the rightand left ventricular outflow tract (RVOT resp. LVOT) and the mitral valve $(M V)$. Isovolumic contraction (IVCT) and relaxation (IVRT) are delayed and prolonged at the expense of both ejection $(E T)$ and filling $(F T)$. Delayed ejection and pressure rise causes diastolic mitral regurgitation $(M R)$. The impaired ventricular filling causes fusion of the early relaxation phase of the ventricle with the atrial contraction leading to E/A fusion. $A V C$ aortic valve closure, $A V O$ aortic valve opening, $M V C$ mitral valve closure, $M V O$ mitral valve opening

evaluates the systolic phase shift by measuring the delay between the onset of RV and LV ejection as derived from pulsed wave Doppler in the RV and LV outflow tract, respectively (Fig. 2). Feasibility and reproducibility of this parameter are very good. Higher IVMD values have consistently been reported to be associated with more reverse remodeling in several large clinical studies [17, 22, 41, 42] 
with cut-offs mostly around 40-49 ms. In the CARE-HF trial, an IVMD of $>40 \mathrm{~ms}$ was one of the inclusion criteria for patients with QRS between 120 and $150 \mathrm{~ms}$ [7]. Within this trial, patients with IVMD $>49$ ms derived statistically more survival benefit from CRT than those with lower values, making it the only marker to date with proven impact on the prognostic success of CRT. Inversely the RethinQ-trial has demonstrated very low IVMD values in patients with narrow QRS and accordingly poor response [18].

Alternative methods to quantify interventricular dyssynchrony based on tissue Doppler delays between the RV and LV free walls have been used $[12,43]$. The incremental value of such locally derived markers over the conventional method, and of local inter- over intraventricular temporal delays, remains disputed $[17,18,28$, 30, 43].

\section{Measurements of regional intraventricular dyssynchrony}

Whereas LV time intervals and IVMD are measurements of global dyssynchrony, regional dyssynchrony measurements inherently relate to delays in distinct events between various specific regions. Over the last decade, several techniques and approaches have been proposed that differ in three respects: (1) they are based on timing of either motion, velocity of motion, or myocardial deformation, (2) either peak or onset events are measured, and (3) the amount of dyssynchrony is assessed by standard deviation of peaks, maximal delay, maximal opposing wall delay or by selective wall delay (e.g. septal-to-lateral wall delay) (Table 1).

Quantification based on tissue motion or tissue velocity delays

Nearly all commonly proposed measurements of regional dyssynchrony are based on the timing of myocardial longitudinal or radial motion or its velocity. To date, motionand velocity-based methods are also the only regional dyssynchrony markers tested and evaluated in multicenter trials $[17,18,44]$.

\section{One-dimensional techniques assessing motion delay}

The septal-to-posterior wall motion delay (SPWMD) selectively measures the delay between the peak inward motion of the septum and that of the posterior wall on parasternal M-mode images at the midventricular level (Fig. 3, panel a). A cut-off of $\geq 130 \mathrm{~ms}$ has initially been proposed to predict both volumetric response as well as clinical outcome after CRT [14, 45]. The method can be applied on all echocardiographic systems without the need for specialized software. Limitations specific to the method consist of problems in achieving an alignment perpendicular to the walls in patients with low parasternal windows (partially amenable by using anatomical M-mode), and measurement difficulties in the presence of severe hypo- or akinesia due to previous infarction or severely compromised radial motion in advanced heart failure. The frequency with which these shortcomings are encountered in the target population for CRT (16-28\%) poses important

Table 1 Measurements of regional delay to predict CRT response

\begin{tabular}{|c|c|c|c|c|c|c|c|c|}
\hline $\begin{array}{l}\text { Author } \\
\text { (Ref.) }\end{array}$ & Parameter & $N$ & Population & $\begin{array}{l}\text { Ischemic } \\
\text { etiology }(\%)\end{array}$ & $\begin{array}{l}\text { Follow-up } \\
\text { (months) }\end{array}$ & Response & Cut-off & $\begin{array}{l}\text { Sensitivity }(\%) / \\
\text { specificity }(\%)\end{array}$ \\
\hline Pitzalis [14] & SPWMD & 20 & $\begin{array}{l}\text { NYHA III, QRS } \geq 140 \mathrm{~ms}, \\
\text { LVEF } \leq 35 \%, \text { SR, LBBB }\end{array}$ & 20 & 1 & LVESV $\geq 15 \%$ & $130 \mathrm{~ms}$ & $100 / 63$ \\
\hline Soliman [50] & 3D-SDI & 90 & $\begin{aligned} \mathrm{NYHA} & \geq \mathrm{III}, \mathrm{QRS} \geq 120 \mathrm{~ms}, \\
\mathrm{LVEF} & \leq 35 \%, \mathrm{SR}\end{aligned}$ & 51 & 12 & LVESV $\geq 15 \%$ & $>10 \%$ & $96 / 88$ \\
\hline $\operatorname{Bax}[12]$ & Ts-4 & 80 & $\begin{array}{c}\mathrm{NYHA} \geq \mathrm{III}, \mathrm{QRS} \geq 120 \mathrm{~ms} \\
\mathrm{LVEF} \leq 35 \%, \mathrm{SR}, \mathrm{LBBB}\end{array}$ & 55 & 6 & $\begin{array}{l}\text { LVESV } \geq 15 \% \\
\text { NYHA } \geq 1\end{array}$ & $\begin{array}{l}65 \mathrm{~ms} \\
65 \mathrm{~ms}\end{array}$ & $\begin{array}{l}92 / 92 \\
80 / 80\end{array}$ \\
\hline Yu [56] & Ts-SD12 & 30 & $\begin{array}{l}\text { NYHA III, QRS } \geq 140 \mathrm{~ms}, \\
\text { LVEF } \leq 40 \%\end{array}$ & 40 & 3 & LVESV $\geq 15 \%$ & $32.6 \mathrm{~ms}$ & $100 / 100$ \\
\hline $\mathrm{Yu}[16]$ & TSI-Ts-SD12 & 56 & $\begin{aligned} \mathrm{NYHA} & \geq \mathrm{III}, \mathrm{QRS} \\
\mathrm{LVEF} & \leq 40 \%\end{aligned}$ & 50 & 3 & LVESV $\geq 15 \%$ & $34.4 \mathrm{~ms}$ & $87 / 81$ \\
\hline Suffoletto [15] & 2D-RS & 50 & $\begin{array}{l}\mathrm{NYHA} \geq \mathrm{III}, \mathrm{QRS} \geq 120 \mathrm{~ms}, \\
\mathrm{LVEF} \leq 35 \%, \mathrm{SR}\end{array}$ & 62 & $8 \pm 5$ & $\mathrm{LVEF} \geq 15 \%$ & $130 \mathrm{~ms}$ & $89 / 83$ \\
\hline
\end{tabular}

$2 D$-RS speckle tracking radial strain, $3 D-S D I$ standard deviation of 16 time-volume peaks, $L B B B$ left bundle branch block, $L V E F$ left ventricle ejection fraction, $L V E S V$ left ventricle end-systolic volume, $N Y H A$ New York Heart Association class, SPWMD M-mode septal to posterior wall motion delay, $S R$ sinus rhythm, Ts-4 maximal velocity delay between 4 basal segments, TSI tissue synchronization imaging, Ts-SD12 standard deviation of velocity peaks in 12 basal and midventricular segments 

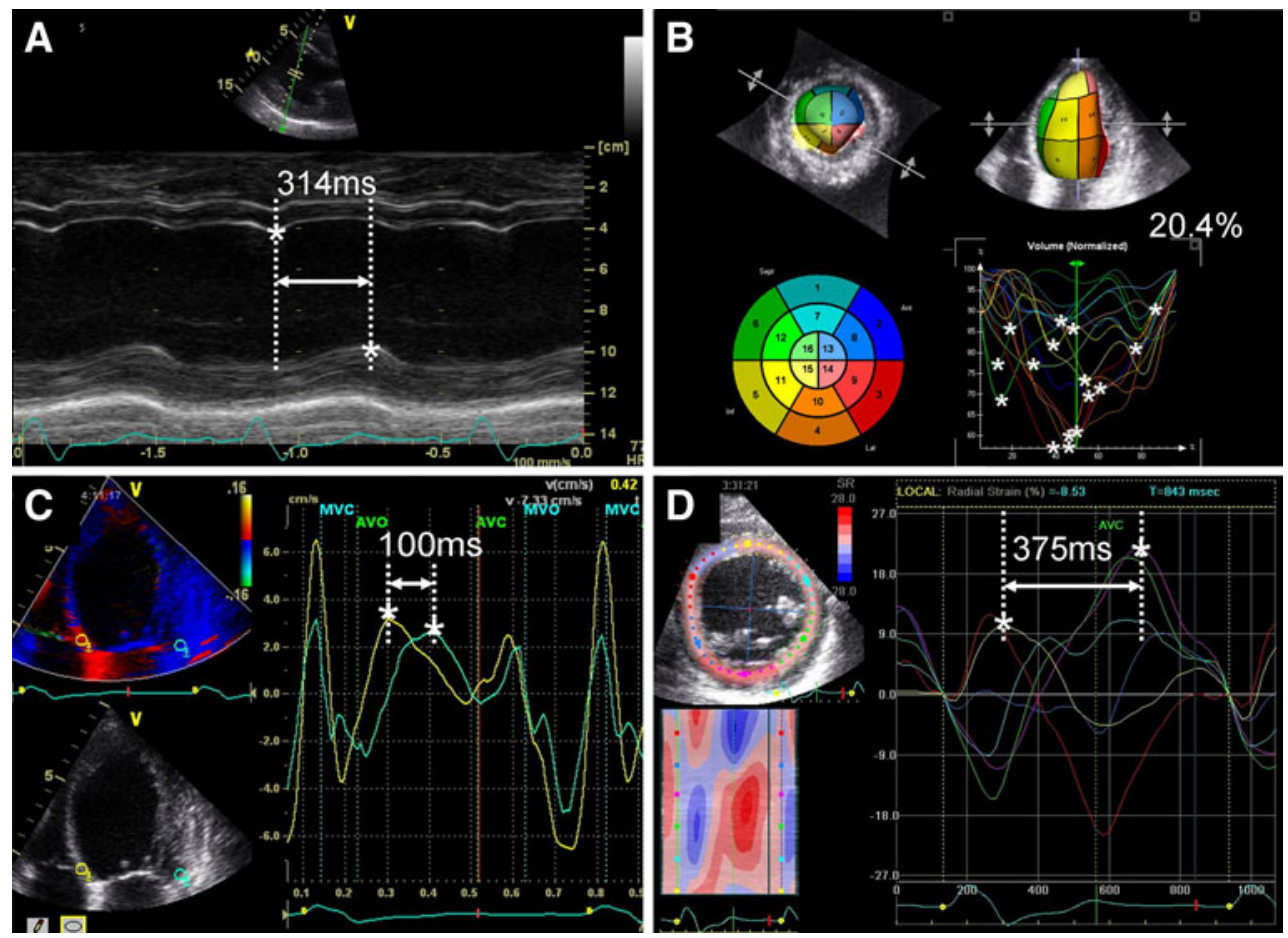

Fig. 3 Approaches to assess regional intraventricular dyssynchrony. Four of the most often applied measurements of regional dyssynchrony are displayed. Asterisks indicate peak measurements. Panel a septal-to-posterior wall motion delay by parasternal M-Mode, panel

difficulties and may explain the negative results in most subsequent studies [17, 44, 46].

Tissue tracking measures the longitudinal displacement of the myocardium with respect to the ultrasound transducer by temporal integration of the tissue Doppler velocity profiles. Dyssynchrony is assessed by determining the location and the number of wall segments with delayed longitudinal displacement (i.e. after aortic valve closure), and by measuring the magnitude of the time delay for each segment $[17,47]$.

\section{Three-dimensional motion delays}

The novel three-dimensional echocardiography technology allows to measure endocardial wall motion with reference to a ventricular center point. An LV volume is obtained by computerized reconstruction of multiple subvolumes acquired in 4-7 consecutive, ECG-triggered cardiac cycles. Tracking of the LV endocardial border is computer assisted, with only the definition of end-diastolic and endsystolic position of the mitral annulus and apex being operator dependent in recent software packages. Regional time-volume curves in $16 \mathrm{LV}$ subvolumes are reconstructed with reference to the ventricular center point, thereby describing ventricular dyssynchrony in terms of regional delays in peak volume displacement throughout b three-dimensional dyssynchrony index derived from three-dimensional echocardiography, panel c tissue Doppler derived septal-tolateral peak systolic velocity delay, panel $\mathbf{d}$ speckle-tracking derived anteroseptal-to-posterior peak radial strain delay

the ventricle. The three-dimensional dyssynchrony index (3D-SDI) quantifies dyssynchrony as the standard deviation of the time to minimum systolic volume as a percentage of cardiac cycle length (Fig. 3, panel b). Most published reports indicate that 3D-SDI adequately predicts reverse remodeling and the acute systolic improvement after CRT [48-50]. An additional advantage of the approach lies in the fact that it integrates dyssynchrony quantification of the whole ventricle within the most accurate and reproducible echocardiographic assessment of LV volumes and ejection fraction used to monitor response. Limitations are the need for a good image quality and a stable heart rhythm [51].

\section{Tissue velocity delays}

Tissue Doppler Imaging (TDI) determines the longitudinal velocity of the tissue with reference to the ultrasound probe from an apical view, either by conventional pulsed-wave TDI or by offline analysis of color-coded TDI images. The time to onset or peak systolic velocity in the investigated segments is measured with reference to the QRS, and the relative delays between these segments are employed as a measure of mechanical dyssynchrony. Whereas timing of onset velocities and the use of pulsed wave velocities have been applied by several investigators [43, 52] measuring the delay between peak velocities within a single high 
frame-rate color-coded TDI image has the advantage of being the more practical and more extensively investigated approach [12, 16, 53-58]. Accordingly, the American society of echocardiography recommends using peak measurements determined by color-coded TDI and restricting the identification of velocity peaks to the ejection period (i.e. between aortic valve opening and closure as determined by Doppler in the LVOT) [33]. Of the many indices that have been proposed, the delay between the (antero-)septum and the opposite (postero-)lateral wall (Fig. 3, panel c, cut-off 60-65 ms) $[12,53]$ and the standard deviation of 12 basal and midventricular velocity peaks derived from the 3 standard apical views (Ts-SD12, cut-off $32 \mathrm{~ms}$ ) [56] have been best evaluated in single center studies as well as in the multicenter setting [17]. A practical way to derive tissue velocities is tissue synchronization imaging (TSI). After manual definition of the regions of interest in two-dimensional or triplane TDI images, this approach automatically detects peak velocities and displays the results in numeric data and color-coded parametric plots $[16,53,55]$. The approach has shown a good correlation with the manual TDI-approach and a similar predictive accuracy [16]. Limitations specific to the TDI-methodology consist of an unclear physiologic correlate for peak velocity timing, and the angle dependency of the method requiring optimal alignment of the tissue with the ultrasound beam. In angulated basal segments therefore, velocity tracings and thus the timing of their peak can change considerably by small changes in the position of the sample volume [59].

\section{General limitations of motion- and velocity-based techniques}

On the assumption that timing of systolic motion and/or velocity in the investigated segment reflects the mechanical activity of the underlying myocardium, TDI and other motion-based methods have not only been proposed to investigate the presence of dyssynchrony but also to detect the site of latest activation or to screen for dyssynchrony in failing hearts with narrow QRS [18, 60]. This core assumption itself, however, is subject to several limitations, most important the inability to differentiate active from passive motion caused by tethering of adjacent segments [61]. This can lead both to apparently inversed activation delays (free wall preceding the septum, e.g. by apical rocking) despite classical $\mathrm{LBBB}$ as well as to apparent or excessive delays even without underlying conduction delays (e.g. by including postsystolic motion in ischemic or infarcted segments) [59, 62, 63]. In particular when acquisitions or measurements are delayed by referencing them to QRS-triggering instead of QRS-onset (as for automated measurements like 3D-SDI), the early and brief lived septal motion typically associated with LBBB is often missed or disregarded and the postsystolic, passive recoil motion is erroneously measured instead. These confounders at least partially explain the high incidence of dyssynchrony in failing hearts without conduction delays reported by these techniques, and the disappointing predictive performance in a number of more recent large studies $[17,18$, 48, 59, 64, 65].

\section{Quantification based on tissue deformation delays}

When compared to motion and velocity-based techniques, measurements of myocardial deformation (strain) provide a superior ability to discriminate active contraction from passive translational motion, and thereby theoretically overcome the most important limitation of the former techniques. Strain can be derived either by postprocessing and temporal integration of color-TDI-derived velocity data or by speckle tracking [66]. TDI-derived strain however suffers from the same angle dependency as the fundamental velocity data from which it is derived, and additionally requires significant expertise to obtain reliable results. In line with these limitations, variable results have been obtained regarding the identification of mechanical dyssynchrony and prediction of CRT outcome [30, 58, 64]. Speckle tracking two-dimensional strain (2DS) relies on the automated tracking of unique speckle patterns generated by the acoustic backscatter interference during standard grey-scale imaging, rendering the technique largely angle independent. Moreover, it is applicable on 2- as well as 3-dimensional datasets and profits from a considerably automated analysis which speeds up analysis time, and improves measurement reproducibility for less experienced operators $[66,67]$. Compared to the traditional gold standard to measure myocardial deformation by magnetic resonance tagging, it has the advantage of providing triggerindependent information throughout systole as well as diastole. Myocardial deformation by 2DS can provide quantification of longitudinal shortening, circumferential shortening, and radial thickening. Suffoletto et al. used radial 2DS to quantify the delay between peak strain of the anteroseptal and posterior wall (Fig. 3, panel d). A cut-off of $130 \mathrm{~ms}$ (as published previously for SPWMD) was found to be predictive for acute increase in stroke volume and longer-term increase in LVEF [15]. The same cut-off was applied in combination with the previously proposed TDI septal-to-lateral delay of $\geq 60 \mathrm{~ms}$ in a subsequent study, demonstrating the superiority of a combined assessment over the single use of any of the two [54]. In analogy with the approaches used for TDI-derived velocities, the standard deviation between multiple segments and analysis of strain in the circumferential and longitudinal 
direction were attempted, but neither proved superior to the radial anteroseptal-to-posterior approach [68].

Considerations and limitations regarding regional temporal dyssynchrony

Regardless of the technique used to derive the fundamental data, the concept and measurement of regional temporal dyssynchrony in itself has some important limitations. First, as opposed to the normal heart, the dyssynchronous and failing heart is characterized by complex and multiphasic mechanical behavior rendering the definition of onsets and peaks much more complex, increasing the measurement variability inherent to echocardiography [17, 30, 59]. As opposed to assessment of global dyssynchrony by cardiac time intervals, echocardiographic indices of regional temporal dyssynchrony suffer from a lower feasibility and a larger variability ( $>20 \%$ in large studies) [17, 30]. Second, as far as the peak of the chosen mechanical event has any intrinsic physiological or functional relevance in the first place, considering only its timing ignores the importance of its extent (amplitude) and overall mechanical impact. Therefore, equal delays in segments with different contractility will result in the same dyssynchrony index, while it is unlikely that they have an equally important mechanical impact. Finally, also the spatial organization of dyssynchrony (random versus clustered) determines how the disturbance translates into an inefficient LV performance, and whether pacing from two opposite sites can be expected to be successful.

\section{Assessment of mechanical dyscoordination and inefficiency}

Whereas dyssynchrony refers merely to delays in onset- or peak mechanical events, discoordination assesses the severity (amplitude) and/or distribution of counteractive mechanical behavior caused by imbalanced forces.

Qualitative appraisal of discoordination-related motion features

The easiest and most readily available method to assess mechanical discoordination is by visual identification of characteristic motion abnormalities associated with LBBB. Both an early and abruptly interrupted or multiphasic contraction of the interventricular septum as well as an abnormal systolic septal-to-lateral shuffling motion of the LV apex have been recognized as motion features associated with LBBB [69, 70]. Both abnormalities can be ascribed to the transmission of contractile force from the early activated and contracting RV and interventricular septum to the still quiescent LV free wall, with reversal of the sequence later in systole. Jansen et al. [71] used both motion abnormalities to predict reverse remodeling with high sensitivity and specificity (Table 2). More recently, a semi-quantitative assessment of abnormal septal motion as part of a multiparametric approach yielded moderate predictive results as a single parameter, but the combination with AV and interventricular dyssynchrony parameters resulted in adequate prediction of response to CRT [31]. More quantitative approaches to indentify subtle forms of LBBB motion abnormalities have recently been applied [70].

Quantification of mechanical discoordination and inefficiency

Quantitative measurements of discoordination introduce phase and (mostly) amplitude information by taking the entire time course of the mechanical process into account, thereby obviating some of the problems inherent to measurements of regional dyssynchrony. Conceptually, these indices express mechanical inefficiency and as argued by Leclerq et al. [23] and Kirn et al. [24] are particularly sensitive to spatially clustered simultaneous shortening and stretching. Several of these indices have first been implemented using magnetic resonance (MR) tagging [23, 24, 72, 106]. The methods applicable to echocardiography include phase analysis of myocardial motion or deformation, assessment of stretch relative to shortening, and selective quantification of inefficient deformation (Table 2; Fig. 4).

\section{Phase analysis of myocardial motion or deformation}

By submitting motion or deformation throughout the ventricle to Fourier analysis, relative (systolic and diastolic) cyclic phase relations between myocardial segments or walls can be assessed. These methods therefore by excellence express the spatial organization of out of phase mechanical behavior without providing information on the amplitude of motion or deformation. Breithardt et al. [73] thus analyzed septal and lateral inward motion, demonstrating a larger out of phase motion to be predictive of acute hemodynamic response to CRT. Extending these findings, Buss et al. [74] demonstrated potential for prediction of reverse remodeling but could not outperform measurements of regional delay. In analogy, the circumferential uniformity ratio estimate (CURE) or temporal uniformity of strain (TUS) implements phase analysis based on deformation, initially implemented on MR-tagging images [23, 75, 76]. In its first application in humans, TUS was able to identify clinical responders with perfect sensitivity [72]. Applied to echocardiographic speckle tracking data and using very strict response criteria ( $\geq 15 \%$ volume reduction and $\geq 25 \%$ LVEF improvement), Bertola et al. 


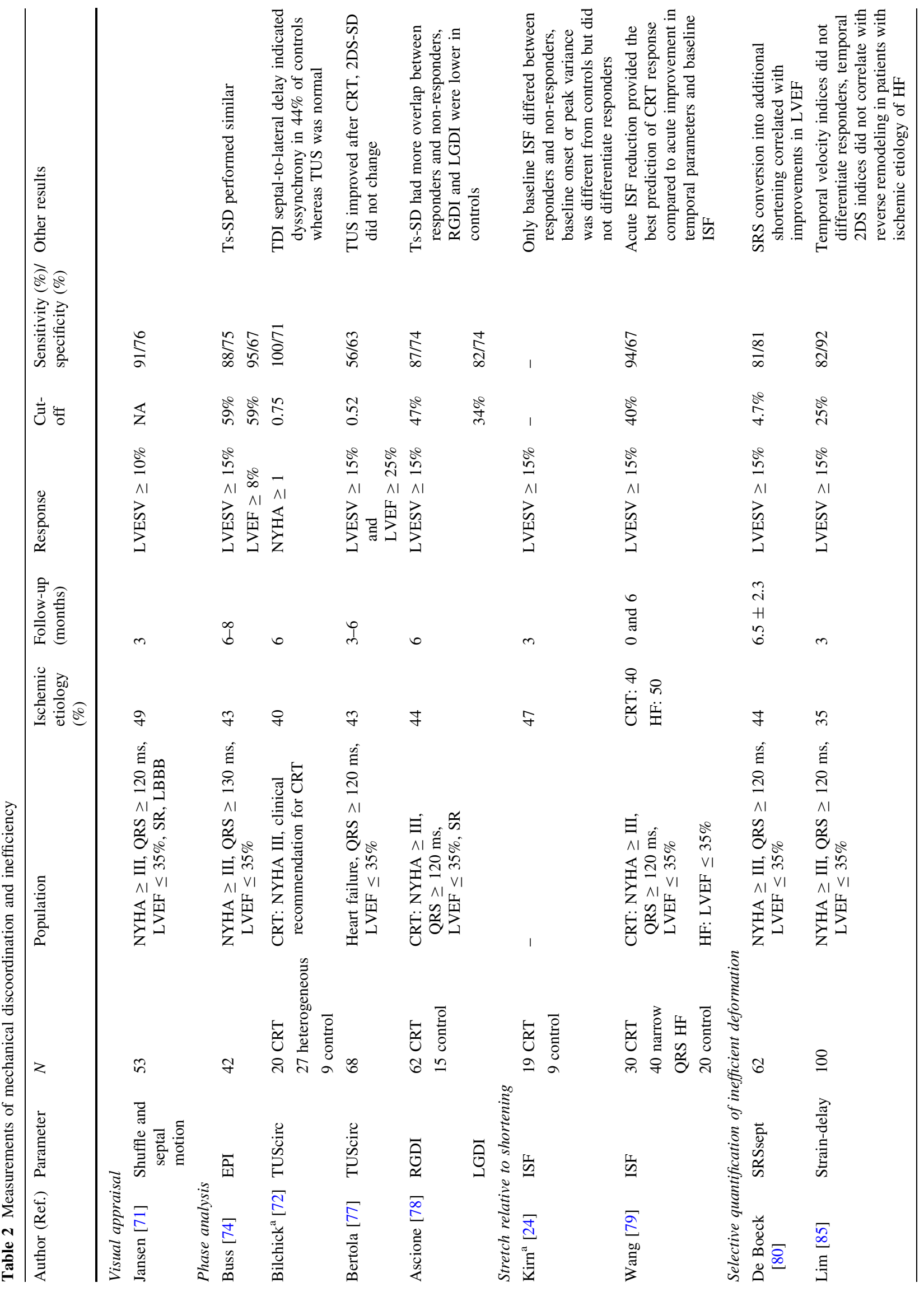




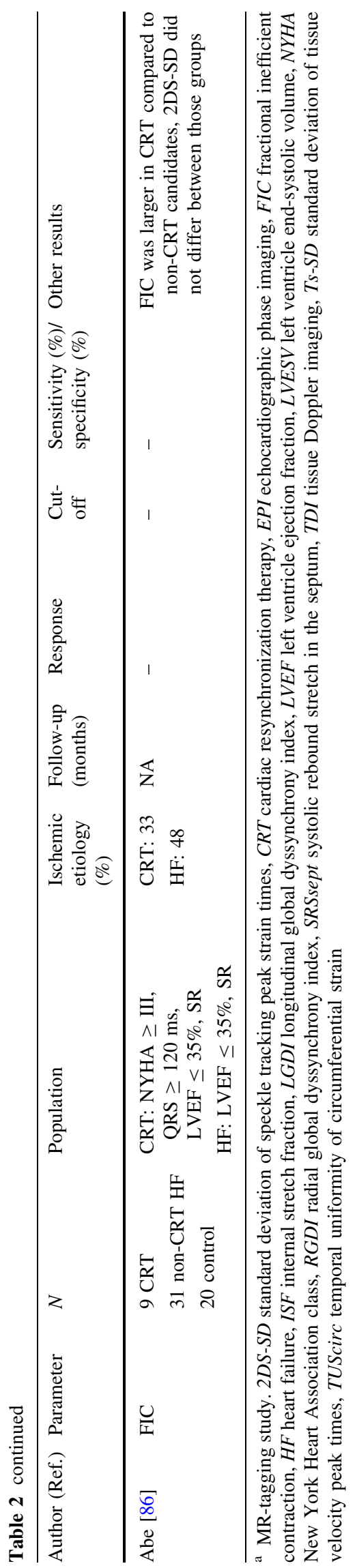

[77] obtained only moderate prediction. A simplified approach, omitting Fourier processing, was presented by Ascione et al. [78] who measured the absolute time duration that basal septal and lateral wall were out of phase (one shortened and the other stretched).

\section{Assessment of stretch relative to shortening}

Also initially designed for and implemented by MR-tagging studies, the internal stretch fraction (ISF) expresses the relative burden of paradoxical stretch during systolic shortening. This requires time differentiation and integration of all myocardial deformation (strain rate data) to obtain an averaged shortening and lengthening signal respectively. In contrast to the previous methods, it therefore incorporates amplitude information. Shortening amplitude thus quantifies the impact of mechanical discoordination on the overall mechanical (dys)function, whereas stretch amplitude (being dependent on local elasticity as well as remote contractile force) indirectly incorporates information on viability and contractility [24]. The superiority of ISF over regional delay measurements was demonstrated by direct comparison of both methods on the same MR-tagging data [24]. Whereas both methods accurately discriminated CRT recipients from healthy controls, only ISF was able to differentiate responders from non-responders. A recent echocardiographic study further extended these findings by demonstrating that acute recoordination (defined as radial ISF decrease) after CRT predicted reverse remodeling after 6 months better than acute resynchronization (defined as radial standard deviation of peak strains). In this latter study, of the baseline variables only ISF was able to predict reverse remodeling [79].

\section{Selective quantification of inefficient deformation}

Whereas phase analysis and ISF assess the ratio of the inefficient component (i.e. reciprocal stretch or out of phase motion) and the efficient component (i.e. systolic shortening or in phase motion), the subsequently discussed methods express and quantify the inefficient component in absolute terms. They thus represent the absolute gain in shortening that would theoretically occur if (peak) shortening was perfectly timed on aortic valve closure.

Systolic rebound stretch (SRS) measurement is in several regards a continuation and specification of the concepts of ISF. It specifically measures only the absolute stretching that occurs after initial shortening and disregards the early stretching associated with delayed and postsystolic shortening. Whereas prestretch and postsystolic shortening can also result from ischemia or excessive loading, early systolic shortening and SRS occur in early activated segments and are highly specific for underlying 
dyssynchronous activation [80-82]. Thus, the aspecific components of discoordination that can also occur in the setting of ischemia or scarring, and that are not or only moderately related to CRT response (Fig. 5), are left out of the analyses [80, 83, 84]. SRS is consistently converted into additional segmental shortening by CRT. The central role of the septum in the pathophysiology of dyssynchrony was confirmed by revealing that the majority of SRS and functional improvements occurred in the septum. In the prediction of reverse remodeling, septal (cut-off $4.7 \%$ ) and total ventricular SRS performed equally well [80].
Rather than selectively measuring systolic stretch, Lim et al. used speckle tracking longitudinal deformation to calculate the sum of the differences between absolute peak values and end-systolic values across 16 segments. By thus incorporating information on prominent diastolic deformation (i.e. diastolic exceeding systolic amplitude) and additionally discarding the information from akinetic or markedly stretched segments, the index (cut-off 25\%) reached sensitivity and specificity of 82 and $92 \%$ respectively for the prediction of reverse remodeling. Especially in patients with ischemic heart failure etiology, it thereby

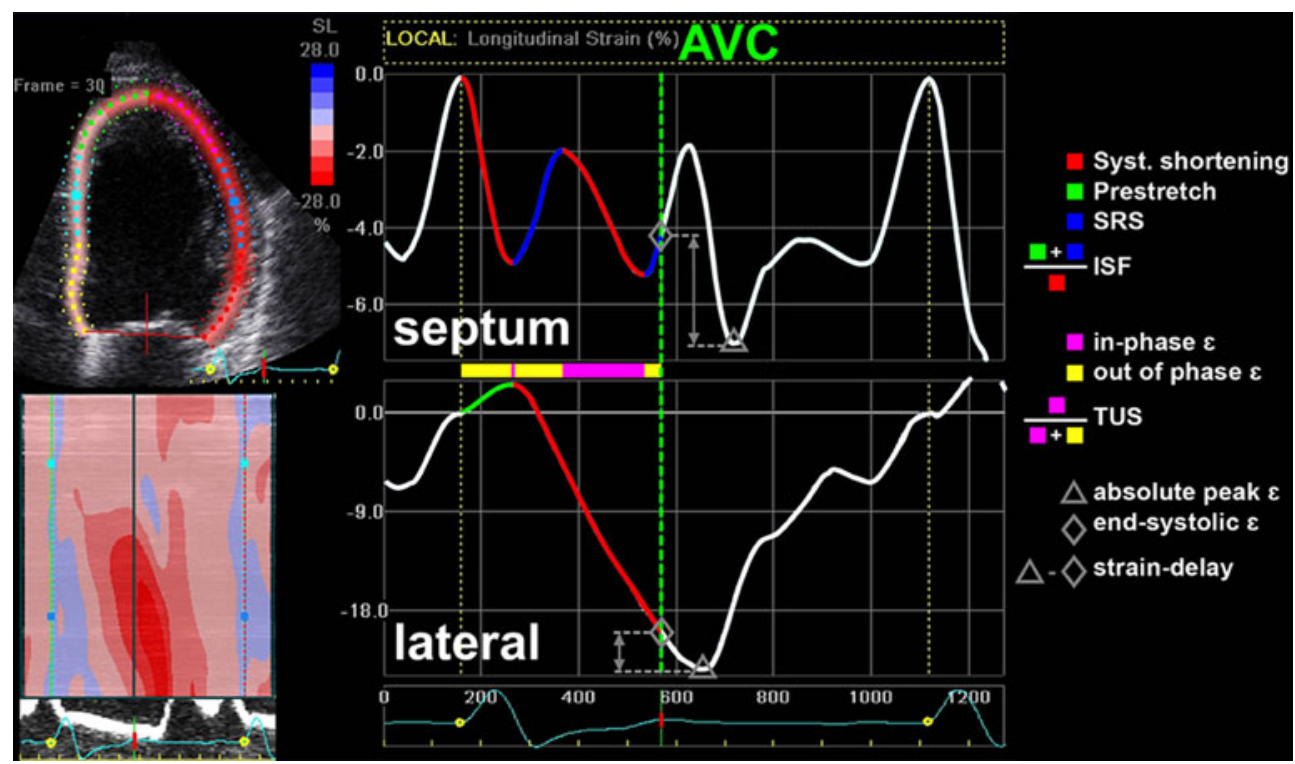

Fig. 4 Approaches to assess mechanical discoordination. Deformation traces of the septum and lateral wall are displayed as derived from speckle tracking. The green vertical dashed line indicates the end of systole as defined by aortic valve closure $(A V C)$. Several concepts of discoordination measurements are illustrated. Notice that assessment of TUS and ISF require either Fourier analysis or time differentiation and integration steps, respectively, that are not displayed in the current figure. $\varepsilon$ strain, ISF internal stretch fraction, $S R S$ systolic rebound stretch, TUS temporal uniformity of strain
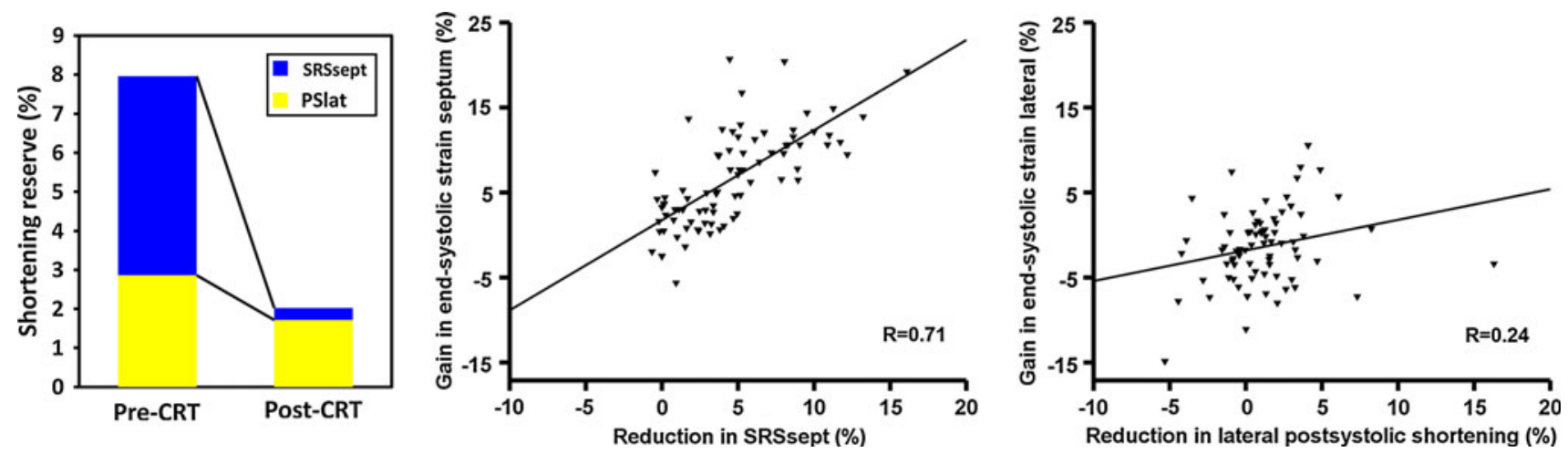

Fig. 5 Conversion of stretch and postsystolic shortening into effective shortening by CRT. Relation of septal systolic rebound stretch (SRSsept) and lateral postsystolic shortening (PSlat) with gain in function are displayed. Left panel shows the effect of CRT on both components of contractile inefficiency: CRT nearly eliminates
SRSsept whereas the effect on PSlat is less pronounced. Middle panel displays the relation of SRSsept reduction with local gain in function. Right panel displays the same relation for PSlat reduction (unpublished data) 
compared favorably to the regional delay methods TDI TsSD12, TDI septal-to-lateral delay, and 2DS 12 segments standard deviation [85].

In an analogous approach, Abe et al. measured segmental and global time-area changes of the myocardium in a midventricular short-axis trace to calculate the fractional inefficient contraction (the fraction by which the summed regional area changes exceed the actual global area change). Their method also compared favorably to regional delay measurements in particular with regard to the blinded differentiation of patients with guideline indication for CRT from those with heart failure but not meeting the guideline criteria [86].

Considerations and limitations regarding discoordination measurements

Although discoordination measurements are designed to represent mechanical inefficiency, its shortening and stretch components are load dependent. Discoordination indices are therefore only indirect markers of (imbalanced) contractile force development and lack information on the ultimate consequences of dyssynchrony on the pressuregenerating ability of the heart. Initial experimental results indicate that elevated wall stress in the setting of progressive dilatation is paralleled by increased variation in regional work and that measurements of discoordination accurately reflect this increased dissipation of work [87]. Seemingly contradictory, explorative patient data indicate that dobutamine induced pre- and afterload reduction (and increased contractility) can unmask mechanical discoordination [88] and the effects of changes in loading and contractility therefore need to be further elucidated. On the other hand, with abnormal stretch and wall stress being important determinants of secondary biological effects of dyssynchrony, the significance of stretch-based indices may reach beyond the purely hemodynamic aspects of CRT. From a practical point of view, discoordination measures are technically challenging and have not been implemented in commercially available software packages [89]. On top of inaccuracies originating from variability in strain amplitude measurement, methodologies selectively assessing dyscoordination in the systolic period are susceptible to errors in delineating and incorporating this temporal component. Feasibility is also an important issue for many of the indices that require sampling large parts of the LV (e.g. CURE, ISF), since echocardiographic approaches are frequently incapable of investigating one or more LV segments or walls. Finally, clinical experience with these indices is promising but still sparse making definite conclusions on their feasibility and value likewise premature.

\section{Unsolved issues}

In which direction to assess dyssynchrony?

The introduction of two- and three-dimensional deformation techniques and the concomitant possibility to assess dyssynchrony and discoordination in the longitudinal, circumferential, and radial direction have compelled investigators to reconsider the optimal direction for the analyses. Whereas circumferential and longitudinal deformation are elicited by shortening of (midmyocardial respectively endo- and epicardial) muscle fibers oriented in these directions, radial thickening is the result of myocardial incompressibility, and thus represents a combined effect of the former two. The superior predictive potential of radial dyssynchrony in echocardiographic studies has mainly been attributed to this combined effect, although differences in sampling location and measurement reliability might also have affected the results $[15,68,90,91]$. From a mathematical point of view, and confirmed by MR-tagging studies, the large dynamic range of circumferential deformation renders it most sensitive to subtle changes in (dys)synchrony [75, 92]. On the other hand, when assessed by echocardiography, longitudinal deformation is of interest especially because of its favorable feasibility and reproducibility compared to the other directions [30]. Additionally, when applied to single walls instead of the (more common) complete apical view, its spatial and temporal resolutions are unmatched by any of the other approaches [80, 81].

The influence of myocardial scar and lead localization

In addition to problems in the recognition of true, amenable dyssynchrony, variability in therapy response introduced by the patients natural disease course, mechanical factors independent of dyssynchrony, and inappropriate delivery of resynchronization make that response prediction cannot be expected to be perfect. The presence of posterolateral scar as well as the total scar burden has been associated with a reduction in response to CRT [13, 93, 94]. The former most likely relates to the inability to obtain an adequate LV lead position, whereas the latter can be related to insufficient viable myocardium to be recruited by CRT $[95,96]$. If advanced scarring is predictive of non-response after CRT, measurements of the amenable substrate for CRT should preferably indicate a decreasing likelihood of response with increasing amounts of myocardial scar. Parameters of mechanical discoordination seem to display this pattern, whereas measurements of QRS-width or markers of temporal dyssynchrony are relatively unaffected (Fig. 6). 


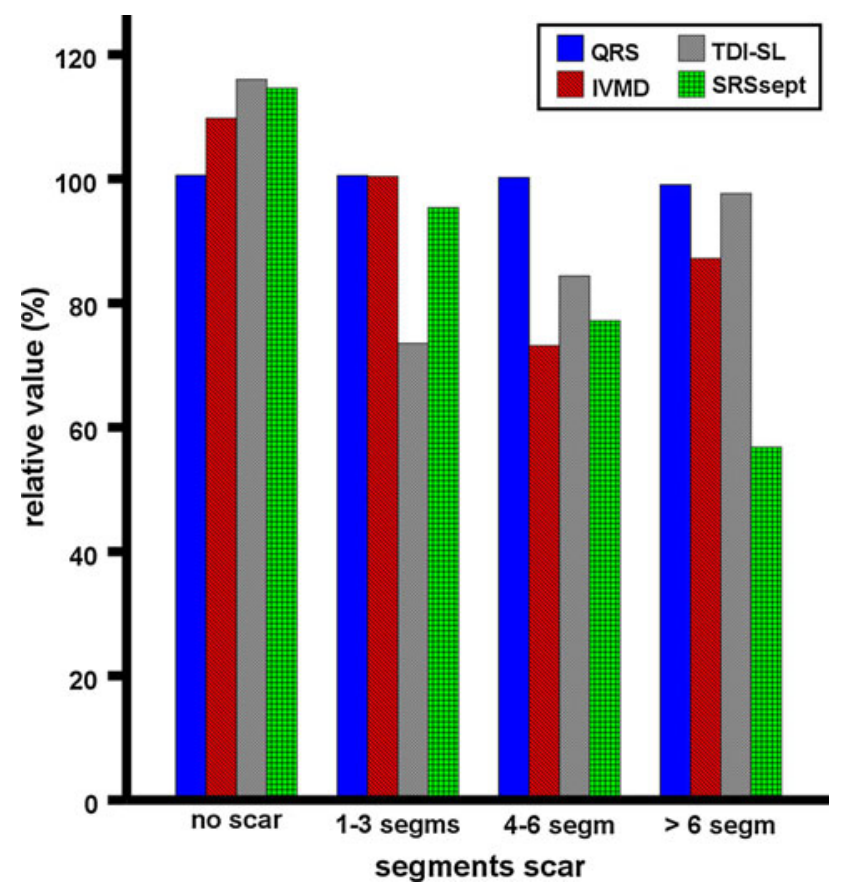

Fig. 6 Scar and dyssynchrony. Normalized baseline values for electrical and mechanical dyssynchrony and discoordination parameters for increasing amounts of scar (population mean used for reference). SRSsept is the only parameter that consistently shows a decrease in dyssynchrony with increasing amounts of scar (unpublished data). IVMD interventricular mechanical delay, SRSsept septal systolic rebound stretch, TDI-SL tissue Doppler septal-to-lateral delay

Apart from the unfavorable lead localization in the area of scar, observational studies have suggested LV lead placement to be optimal in the most mechanically delayed segment $[60,97]$. This suggestion has recently been refuted by an experimental study that demonstrated optimal lead position to coincide with the site of most pronounced electrical resynchronization rather than with the site of most mechanical delay [96]. Currently, there is no role for echocardiography in determining the optimal site for LV lead placement.

\section{Echocardiography to extend the indications for CRT}

Although single center studies have suggested echocardiography as an additional screening to extend the application of CRT to patients with narrow-QRS heart failure, this could not be confirmed in a large prospective study $[18,98]$. To prevent more such negative results, validation of proposed parameters in a normal control population should reduce the chance of false positives and prevent the heedless implementation of insufficiently validated parameters [64]. More recently, several investigators have accordingly incorporated normal controls in their analyses, demonstrating adequate differentiation of patients and controls by measurements of discoordination, but not by measurements of regional delay [72].

Definition of response

One of the most important issues that requires clarification is the definition of response. The most relevant response within a heart failure population lies within the improvement of symptoms, heart failure hospitalizations, and reduction in mortality. In an attempt to circumvent the placebo effect of CRT observed in the clinical trials, many echocardiographic studies have disregarded these outcomes and used surrogate endpoints like reverse remodeling and LVEF improvement instead. This methodology has been justified by demonstrating a relation between reverse remodeling and long-term mortality benefit after CRT both in observational studies [99] as well as in recent large multicenter randomized trials [100]. Nevertheless, reverse remodeling may not be necessary for long-term response $[8,22,101]$ and in the CARE-HF trial decreased neurohormonal activation proved to be even more closely linked to prognosis [102]. The issue is further complicated by the poor agreement among different response criteria [103] and the inability of the observational study designs to differentiate genuine response from the spontaneous course of disease [22]. It is likely that a spectrum of responses ranging from only symptom reduction to complete reverse remodeling exists and classification should preferably cover the broad spectrum of this response.

\section{Conclusion}

Echocardiography may play an important role in patient assessment before CRT and is currently one of the most commonly used non-invasive imaging modalities to provide information on its mechanical effects in heart failure patients. Despite recent negative results, echocardiographic techniques have continued to develop with new discoordination approaches benefiting from an improved ability to specifically detect only the amenable substrate for CRT. To make these techniques a valuable addition also to the clinical field, further improvements in measurement feasibility and reliability, a better understanding of the effects of loading and wall stress, and multicenter validation are required. Although the complexity of the disease and its therapy make perfect prediction unlikely, there is no doubt that the mechanical assessment of dyssynchrony will continue to provide additional insight into the disease process and help to optimize therapy delivery.

Open Access This article is distributed under the terms of the Creative Commons Attribution Noncommercial License which 
permits any noncommercial use, distribution, and reproduction in any medium, provided the original author(s) and source are credited.

\section{References}

1. Prinzen FW, Hunter WC, Wyman BT et al (1999) Mapping of regional myocardial strain and work during ventricular pacing: experimental study using magnetic resonance imaging tagging. J Am Coll Cardiol 33(6):1735-1742

2. Vernooy K, Verbeek XA, Peschar M et al (2005) Left bundle branch block induces ventricular remodelling and functional septal hypoperfusion. Eur Heart J 26(1):91-98

3. Wyman BT, Hunter WC, Prinzen FW et al (2002) Effects of single- and biventricular pacing on temporal and spatial dynamics of ventricular contraction. Am J Physiol Heart Circ Physiol 282(1):H372-H379

4. Vernooy K, Cornelussen RN, Verbeek XA et al (2007) Cardiac resynchronization therapy cures dyssynchronopathy in canine left bundle-branch block hearts. Eur Heart J 28(17):2148-2155

5. Vanderheyden M, Mullens W, Delrue L et al (2008) Myocardial gene expression in heart failure patients treated with cardiac resynchronization therapy responders versus nonresponders. J Am Coll Cardiol 51(2):129-136

6. Abraham WT, Fisher WG, Smith AL et al (2002) Cardiac resynchronization in chronic heart failure. $\mathrm{N}$ Engl $\mathrm{J}$ Med 346(24):1845-1853

7. Cleland JG, Daubert JC, Erdmann E et al (2005) The effect of cardiac resynchronization on morbidity and mortality in heart failure. N Engl J Med 352(15):1539-1549

8. St John Sutton MG, Plappert T, Abraham WT et al (2003) Effect of cardiac resynchronization therapy on left ventricular size and function in chronic heart failure. Circulation 107(15):1985-1990

9. Moss AJ, Hall WJ, Cannom DS et al (2009) Cardiac-resynchronization therapy for the prevention of heart-failure events. N Engl J Med 361(14):1329-1338

10. St John Sutton MG, Ghio S, Plappert T et al (2009) Cardiac resynchronization induces major structural and functional reverse remodeling in patients with New York Heart Association class I/II heart failure. Circulation 120(19):1858-1865

11. Achilli A, Peraldo C, Sassara M et al (2006) Prediction of response to cardiac resynchronization therapy: the selection of candidates for CRT (SCART) study. Pacing Clin Electrophysiol 29(Suppl 2):S11-S19

12. Bax JJ, Bleeker GB, Marwick TH et al (2004) Left ventricular dyssynchrony predicts response and prognosis after cardiac resynchronization therapy. J Am Coll Cardiol 44(9):1834-1840

13. Bleeker GB, Kaandorp TA, Lamb HJ et al (2006) Effect of posterolateral scar tissue on clinical and echocardiographic improvement after cardiac resynchronization therapy. Circulation 113(7):969-976

14. Pitzalis MV, Iacoviello M, Romito R et al (2002) Cardiac resynchronization therapy tailored by echocardiographic evaluation of ventricular asynchrony. J Am Coll Cardiol 40(9): $1615-1622$

15. Suffoletto MS, Dohi K, Cannesson M et al (2006) Novel speckletracking radial strain from routine black-and-white echocardiographic images to quantify dyssynchrony and predict response to cardiac resynchronization therapy. Circulation 113(7):960-968

16. Yu CM, Zhang Q, Fung JW et al (2005) A novel tool to assess systolic asynchrony and identify responders of cardiac resynchronization therapy by tissue synchronization imaging. J Am Coll Cardiol 45(5):677-684

17. Chung ES, Leon AR, Tavazzi L et al (2008) Results of the Predictors of Response to CRT (PROSPECT) trial. Circulation 117(20):2608-2616
18. Beshai JF, Grimm RA, Nagueh SF et al (2007) Cardiac-resynchronization therapy in heart failure with narrow QRS complexes. N Engl J Med 357(24):2461-2471

19. Hawkins NM, Petrie MC, Burgess MI et al (2009) Selecting patients for cardiac resynchronization therapy: the fallacy of echocardiographic dyssynchrony. J Am Coll Cardiol 53(21): 1944-1959

20. van der Land V, Germans T, van Dijk J et al (2007) The effect of left bundle branch block on left ventricular remodeling, dyssynchrony and deformation of the mitral valve apparatus: an observational cardiovascular magnetic resonance imaging study. Int J Cardiovasc Imaging 23(4):529-536

21. Duncan AM, Francis DP, Henein MY et al (2003) Limitation of cardiac output by total isovolumic time during pharmacologic stress in patients with dilated cardiomyopathy: activation-mediated effects of left bundle branch block and coronary artery disease. J Am Coll Cardiol 41(1):121-128

22. Cleland J, Freemantle N, Ghio S et al (2008) Predicting the long-term effects of cardiac resynchronization therapy on mortality from baseline variables and the early response a report from the CARE-HF (Cardiac Resynchronization in Heart Failure) Trial. J Am Coll Cardiol 52(6):438-445

23. Leclercq C, Faris O, Tunin R et al (2002) Systolic improvement and mechanical resynchronization does not require electrical synchrony in the dilated failing heart with left bundle-branch block. Circulation 106(14):1760-1763

24. Kirn B, Jansen A, Bracke F et al (2008) Mechanical discoordination rather than dyssynchrony predicts reverse remodeling upon cardiac resynchronization. Am J Physiol Heart Circ Physiol 295(2):H640-H646

25. Nelson GS, Curry CW, Wyman BT et al (2000) Predictors of systolic augmentation from left ventricular preexcitation in patients with dilated cardiomyopathy and intraventricular conduction delay. Circulation 101(23):2703-2709

26. Auricchio A, Ding J, Spinelli JC et al (2002) Cardiac resynchronization therapy restores optimal atrioventricular mechanical timing in heart failure patients with ventricular conduction delay. J Am Coll Cardiol 39(7):1163-1169

27. Jansen AH, van DJ, Bracke F et al (2007) Improvement in diastolic function and left ventricular filling pressure induced by cardiac resynchronization therapy. Am Heart J 153(5):843-849

28. Duncan AM, Lim E, Clague J et al (2006) Comparison of segmental and global markers of dyssynchrony in predicting clinical response to cardiac resynchronization. Eur Heart J 27(20): 2426-2432

29. Yu CM, Chau E, Sanderson JE et al (2002) Tissue Doppler echocardiographic evidence of reverse remodeling and improved synchronicity by simultaneously delaying regional contraction after biventricular pacing therapy in heart failure. Circulation 105(4):438-445

30. Miyazaki C, Redfield MM, Powell BD et al (2010) Dyssynchrony indices to predict response to cardiac resynchronization therapy: a comprehensive prospective single-center study. Circ Heart Fail 3(5):565-573

31. Parsai C, Bijnens B, Sutherland GR et al (2009) Toward understanding response to cardiac resynchronization therapy: left ventricular dyssynchrony is only one of multiple mechanisms. Eur Heart J 30(8):940-949

32. Lafitte S, Reant P, Zaroui A et al (2009) Validation of an echocardiographic multiparametric strategy to increase responders patients after cardiac resynchronization: a multicentre study. Eur Heart J 30(23):2880-2887

33. Gorcsan J III, Abraham T, Agler DA et al (2008) Echocardiography for cardiac resynchronization therapy: recommendations for performance and reporting-a report from the American Society of Echocardiography Dyssynchrony Writing Group 
endorsed by the Heart Rhythm Society. J Am Soc Echocardiogr 21(3):191-213

34. Stanton T, Hawkins NM, Hogg KJ et al (2008) How should we optimize cardiac resynchronization therapy? Eur Heart J 29(20): $2458-2472$

35. Vernooy K, Verbeek XA, Cornelussen RN et al (2007) Calculation of effective VV interval facilitates optimization of $\mathrm{AV}$ delay and VV interval in cardiac resynchronization therapy. Heart Rhythm 4(1):75-82

36. Little WC, Reeves RC, Arciniegas J et al (1982) Mechanism of abnormal interventricular septal motion during delayed left ventricular activation. Circulation 65(7):1486-1491

37. Yu Y, Kramer A, Spinelli J et al (2003) Biventricular mechanical asynchrony predicts hemodynamic effect of uni- and biventricular pacing. Am J Physiol Heart Circ Physiol 285(6):H2788-H2796

38. Bleasdale RA, Turner MS, Mumford CE et al (2004) Left ventricular pacing minimizes diastolic ventricular interaction, allowing improved preload-dependent systolic performance. Circulation 110(16):2395-2400

39. Lumens J, Arts T, Broers B et al (2009) Right ventricular free wall pacing improves cardiac pump function in severe pulmonary arterial hypertension: a computer simulation analysis. Am J Physiol Heart Circ Physiol 297(6):H2196-H2205

40. Verbeek XA, Auricchio A, Yu Y et al (2006) Tailoring cardiac resynchronization therapy using interventricular asynchrony. Validation of a simple model. Am J Physiol Heart Circ Physiol 290(3):H968-H977

41. Ghio S, Freemantle N, Scelsi L et al (2009) Long-term left ventricular reverse remodelling with cardiac resynchronization therapy: results from the CARE-HF trial. Eur J Heart Fail 11(5): 480-488

42. Richardson M, Freemantle N, Calvert MJ et al (2007) Predictors and treatment response with cardiac resynchronization therapy in patients with heart failure characterized by dyssynchrony: a pre-defined analysis from the CARE-HF trial. Eur Heart $\mathbf{J}$ 28(15):1827-1834

43. Penicka M, Bartunek J, De Bruyne B et al (2004) Improvement of left ventricular function after cardiac resynchronization therapy is predicted by tissue Doppler imaging echocardiography. Circulation 109(8):978-983

44. Marcus GM, Rose E, Viloria EM et al (2005) Septal to posterior wall motion delay fails to predict reverse remodeling or clinical improvement in patients undergoing cardiac resynchronization therapy. J Am Coll Cardiol 46(12):2208-2214

45. Pitzalis MV, Iacoviello M, Romito R et al (2005) Ventricular asynchrony predicts a better outcome in patients with chronic heart failure receiving cardiac resynchronization therapy. J Am Coll Cardiol 45(1):65-69

46. Diaz-Infante E, Sitges M, Vidal B et al (2007) Usefulness of ventricular dyssynchrony measured using M-mode echocardiography to predict response to resynchronization therapy. Am J Cardiol 100(1):84-89

47. Sogaard P, Egeblad H, Pedersen AK et al (2002) Sequential versus simultaneous biventricular resynchronization for severe heart failure: evaluation by tissue Doppler imaging. Circulation 106(16):2078-2084

48. Kapetanakis S, Kearney MT, Siva A et al (2005) Real-time three-dimensional echocardiography: a novel technique to quantify global left ventricular mechanical dyssynchrony. Circulation 112(7):992-1000

49. Marsan NA, Bleeker GB, Ypenburg C et al (2008) Real-time three-dimensional echocardiography as a novel approach to assess left ventricular and left atrium reverse remodeling and to predict response to cardiac resynchronization therapy. Heart Rhythm 5(9):1257-1264
50. Soliman OI, Geleijnse ML, Theuns DA et al (2009) Usefulness of left ventricular systolic dyssynchrony by real-time three-dimensional echocardiography to predict long-term response to cardiac resynchronization therapy. Am J Cardiol 103(11):1586-1591

51. Burgess MI, Jenkins C, Chan J et al (2007) Measurement of left ventricular dyssynchrony in patients with ischaemic cardiomyopathy: a comparison of real-time three-dimensional and tissue Doppler echocardiography. Heart 93(10):1191-1196

52. Soliman OI, Theuns DA, Geleijnse ML et al (2007) Spectral pulsed-wave tissue Doppler imaging lateral-to-septal delay fails to predict clinical or echocardiographic outcome after cardiac resynchronization therapy. Europace 9(2):113-118

53. Gorcsan J III, Kanzaki H, Bazaz R et al (2004) Usefulness of echocardiographic tissue synchronization imaging to predict acute response to cardiac resynchronization therapy. Am J Cardiol 93(9):1178-1181

54. Gorcsan J III, Tanabe M, Bleeker GB et al (2007) Combined longitudinal and radial dyssynchrony predicts ventricular response after resynchronization therapy. J Am Coll Cardiol 50(15):1476-1483

55. Van de Veire NR, Yu CM, Ajmone-Marsan N et al (2008) Triplane tissue Doppler imaging: a novel three-dimensional imaging modality that predicts reverse left ventricular remodelling after cardiac resynchronisation therapy. Heart 94(3):e9

56. Yu CM, Fung WH, Lin H et al (2003) Predictors of left ventricular reverse remodeling after cardiac resynchronization therapy for heart failure secondary to idiopathic dilated or ischemic cardiomyopathy. Am J Cardiol 91(6):684-688

57. Yu CM, Fung JW, Zhang Q et al (2004) Tissue Doppler imaging is superior to strain rate imaging and postsystolic shortening on the prediction of reverse remodeling in both ischemic and nonischemic heart failure after cardiac resynchronization therapy. Circulation 110(1):66-73

58. Yu CM, Gorcsan J III, Bleeker GB et al (2007) Usefulness of tissue Doppler velocity and strain dyssynchrony for predicting left ventricular reverse remodeling response after cardiac resynchronization therapy. Am J Cardiol 100(8):1263-1270

59. De Boeck BW, Meine M, Leenders GE et al (2008) Practical and conceptual limitations of tissue Doppler imaging to predict reverse remodelling in cardiac resynchronisation therapy. Eur $\mathbf{J}$ Heart Fail 10(3):281-290

60. Ansalone G, Giannantoni P, Ricci R et al (2002) Doppler myocardial imaging to evaluate the effectiveness of pacing sites in patients receiving biventricular pacing. J Am Coll Cardiol 39(3):489-499

61. Seo Y, Ishizu T, Sakamaki F et al (2009) Analysis of the origin of cardiac wall motion that constitutes myocardial velocity-time curves in patients with left bundle branch block. J Am Soc Echocardiogr 22(4):331-336

62. Anderson LJ, Miyazaki C, Sutherland GR et al (2008) Patient selection and echocardiographic assessment of dyssynchrony in cardiac resynchronization therapy. Circulation 117(15):2009-2023

63. Breithardt OA, Stellbrink C, Herbots L et al (2003) Cardiac resynchronization therapy can reverse abnormal myocardial strain distribution in patients with heart failure and left bundle branch block. J Am Coll Cardiol 42(3):486-494

64. Miyazaki C, Powell BD, Bruce CJ et al (2008) Comparison of echocardiographic dyssynchrony assessment by tissue velocity and strain imaging in subjects with or without systolic dysfunction and with or without left bundle-branch block. Circulation 117(20):2617-2625

65. Russell K, Opdahl A, Remme EW et al (2010) Evaluation of left ventricular dyssynchrony by onset of active myocardial force generation: a novel method that differentiates between electrical and mechanical etiologies. Circ Cardiovasc Imaging 3(4):405-414 
66. Teske AJ, De Boeck BW, Melman PG et al (2007) Echocardiographic quantification of myocardial function using tissue deformation imaging, a guide to image acquisition and analysis using tissue Doppler and speckle tracking. Cardiovasc Ultrasound 5:27

67. Tanaka H, Hara H, Saba S et al (2010) Usefulness of threedimensional speckle tracking strain to quantify dyssynchrony and the site of latest mechanical activation. Am J Cardiol 105(2):235-242

68. Delgado V, Ypenburg C, Van Bommel RJ et al (2008) Assessment of left ventricular dyssynchrony by speckle tracking strain imaging comparison between longitudinal, circumferential, and radial strain in cardiac resynchronization therapy. J Am Coll Cardiol 51(20):1944-1952

69. McDonald IG (1973) Echocardiographic demonstration of abnormal motion of the interventricular septum in left bundle branch block. Circulation 48(2):272-280

70. Voigt JU, Schneider TM, Korder S et al (2009) Apical transverse motion as surrogate parameter to determine regional left ventricular function inhomogeneities: a new, integrative approach to left ventricular asynchrony assessment. Eur Heart J 30(8): 959-968

71. Jansen AH, van Dantzig JM, Bracke F et al (2007) Qualitative observation of left ventricular multiphasic septal motion and septal-to-lateral apical shuffle predicts left ventricular reverse remodeling after cardiac resynchronization therapy. Am J Cardiol 99(7):966-969

72. Bilchick KC, Dimaano V, Wu KC et al (2008) Cardiac magnetic resonance assessment of dyssynchrony and myocardial scar predicts function class improvement following cardiac resynchronization therapy. JACC Cardiovasc Imaging 1(5):561-568

73. Breithardt OA, Stellbrink C, Kramer AP et al (2002) Echocardiographic quantification of left ventricular asynchrony predicts an acute hemodynamic benefit of cardiac resynchronization therapy. J Am Coll Cardiol 40(3):536-545

74. Buss SJ, Humpert PM, Bekeredjian R et al (2009) Echocardiographic phase imaging to predict reverse remodeling after cardiac resynchronization therapy. JACC Cardiovasc Imaging 2(5): 535-543

75. Helm RH, Leclercq C, Faris OP et al (2005) Cardiac dyssynchrony analysis using circumferential versus longitudinal strain: implications for assessing cardiac resynchronization. Circulation 111(21):2760-2767

76. Lardo AC, Abraham TP, Kass DA (2005) Magnetic resonance imaging assessment of ventricular dyssynchrony: current and emerging concepts. J Am Coll Cardiol 46(12):2223-2228

77. Bertola B, Rondano E, Sulis M et al (2009) Cardiac dyssynchrony quantitated by time-to-peak or temporal uniformity of strain at longitudinal, circumferential, and radial level: implications for resynchronization therapy. J Am Soc Echocardiogr 22(6):665-671

78. Ascione L, Iengo R, Accadia M et al (2008) A radial global dyssynchrony index as predictor of left ventricular reverse remodeling after cardiac resynchronization therapy. Pacing Clin Electrophysiol 31(7):819-827

79. Wang CL, Wu CT, Yeh YHet al (2010) Recoordination rather than resynchronization predicts reverse remodeling after cardiac resynchronization therapy. J Am Soc Echocardiogr 23(6):611-620

80. De Boeck BW, Teske AJ, Meine M et al (2009) Septal rebound stretch reflects the functional substrate to cardiac resynchronization therapy and predicts volumetric and neurohormonal response. Eur J Heart Fail 11(9):863-871

81. De Boeck BW, Teske AJ, Leenders GE et al (2010) Detection and quantification by deformation imaging of the functional impact of septal compared to free wall preexcitation in the Wolff-ParkinsonWhite Syndrome. Am J Cardiol 106(4):539-546
82. Wyman BT, Hunter WC, Prinzen FW et al (1999) Mapping propagation of mechanical activation in the paced heart with MRI tagging. Am J Physiol 276(3 Pt 2):H881-H891

83. Rutz AK, Manka R, Kozerke S et al (2009) Left ventricular dyssynchrony in patients with left bundle branch block and patients after myocardial infarction: integration of mechanics and viability by cardiac magnetic resonance. Eur Heart J 30(17): 2117-2127

84. Skulstad H, Edvardsen T, Urheim S et al (2002) Postsystolic shortening in ischemic myocardium: active contraction or passive recoil? Circulation 106(6):718-724

85. Lim P, Buakhamsri A, Popovic ZB et al (2008) Longitudinal strain delay index by speckle tracking imaging: a new marker of response to cardiac resynchronization therapy. Circulation 118(11):1130-1137

86. Abe Y, Yagishita D, Tagawa Y et al (2010) A novel echocardiographic index of inefficient left ventricular contraction resulting from mechanical dyssynchrony. J Cardiol 55(2):248-255

87. Kerckhoffs RC, Omens JH, McCulloch AD et al (2010) Ventricular dilation and electrical dyssynchrony synergistically increase regional mechanical nonuniformity but not mechanical dyssynchrony: a computational model. Circ Heart Fail 3(4):528-536

88. Parsai C, Baltabaeva A, Anderson L et al (2009) Low-dose dobutamine stress echo to quantify the degree of remodelling after cardiac resynchronization therapy. Eur Heart J 30(8):950-958

89. De Boeck BW, Kirn B, Teske AJ et al (2008) Three-dimensional mapping of mechanical activation patterns, contractile dyssynchrony and dyscoordination by two-dimensional strain echocardiography: rationale and design of a novel software toolbox. Cardiovasc Ultrasound 6:22

90. Sengupta PP, Khandheria BK, Korinek J et al (2006) Apex-tobase dispersion in regional timing of left ventricular shortening and lengthening. J Am Coll Cardiol 47(1):163-172

91. Tanaka H, Nesser HJ, Buck T et al (2010) Dyssynchrony by speckle-tracking echocardiography and response to cardiac resynchronization therapy: results of the Speckle Tracking and Resynchronization (STAR) study. Eur Heart J 31(14): 1690-1700

92. Waldman LK, Nosan D, Villarreal F et al (1988) Relation between transmural deformation and local myofiber direction in canine left ventricle. Circ Res 63(3):550-562

93. Mele D, Agricola E, Galderisi M et al (2009) Echocardiographic myocardial scar burden predicts response to cardiac resynchronization therapy in ischemic heart failure. J Am Soc Echocardiogr 22(6):702-708

94. White JA, Yee R, Yuan X et al (2006) Delayed enhancement magnetic resonance imaging predicts response to cardiac resynchronization therapy in patients with intraventricular dyssynchrony. J Am Coll Cardiol 48(10):1953-1960

95. Marsan NA, Westenberg JJ, Ypenburg C et al (2009) Magnetic resonance imaging and response to cardiac resynchronization therapy: relative merits of left ventricular dyssynchrony and scar tissue. Eur Heart J 30(19):2360-2367

96. Rademakers LM, van KR, van Deursen CJ et al (2010) Myocardial infarction does not preclude electrical and hemodynamic benefits of cardiac resynchronization therapy in dyssynchronous canine hearts. Circ Arrhythm Electrophysiol 3(4):361-368

97. Becker M, Kramann R, Franke A et al (2007) Impact of left ventricular lead position in cardiac resynchronization therapy on left ventricular remodelling. A circumferential strain analysis based on 2D echocardiography. Eur Heart J 28(10):1211-1220

98. Yu CM, Chan YS, Zhang Q et al (2006) Benefits of cardiac resynchronization therapy for heart failure patients with narrow QRS complexes and coexisting systolic asynchrony by echocardiography. J Am Coll Cardiol 48(11):2251-2257

99. Yu CM, Bleeker GB, Fung JW et al (2005) Left ventricular reverse remodeling but not clinical improvement predicts long- 
term survival after cardiac resynchronization therapy. Circulation 112(11):1580-1586

100. Solomon SD, Foster E, Bourgoun M et al (2010) Effect of cardiac resynchronization therapy on reverse remodeling and relation to outcome: multicenter automatic defibrillator implantation trial: cardiac resynchronization therapy. Circulation 122(10):985-992

101. Wikstrom G, Blomstrom-Lundqvist C, Andren B et al (2009) The effects of aetiology on outcome in patients treated with cardiac resynchronization therapy in the CARE-HF trial. Eur Heart J 30(7):782-788

102. Fruhwald FM, Fahrleitner-Pammer A, Berger R et al (2007) Early and sustained effects of cardiac resynchronization therapy on $\mathrm{N}$-terminal pro-B-type natriuretic peptide in patients with moderate to severe heart failure and cardiac dyssynchrony. Eur Heart J 28(13):1592-1597

103. Fornwalt BK, Sprague WW, BeDell P et al (2010) Agreement is poor among current criteria used to define response to cardiac resynchronization therapy. Circulation 121(18):1985-1991

104. Prinzen FW, Vernooy K, DeBoeck BWL et al (in press) Mechano-energetics of the asynchronous and resynchronized heart. Heart Fail Rev. doi:10.1007/s10741-010-9205-3

105. Vanderheyden M, Vrints C, Bartunek J (in press) The molecular fingerprint of cardiac dyssynchrony and cardiac resynchronization therapy. Heart Fail Rev. doi:10.1007/s10741-010-9199-x

106. Leyva F, Foley P (in review) Current and future role of cardiovascular magnetic resonance in cardiac resynchronization therapy. Heart Fail Rev 